LOPEZ ATXURRA ${ }^{1}$, R. La enseñanza de la historia y el pacto de ciudadanía: interrogantes y problemas. ARBAIZA, M.; PEREZ FUENTES, P. Historia e identidades nacionales. Hacia un pacto entre la ciudadanía vasca. Bilbao: Edit. Servicios Redaccionales Bilbainos (SRB), p. 138-159, $2007^{2}$.

\title{
O ENSINO DA HISTÓRIA E O PACTO DE CIDADANIA: QUESTÕES E PROBLEMAS
}

\author{
Érica da Silva Xavier (tradutora) $)^{3}$
}

\section{Introdução}

O ensino de história a partir da perspectiva de educação para a cidadania constitui um a preocupação social e educativa cada vez mais relevante, por isso é objeto de debates acalorados. O passado como objeto de transmissão, o presente como cenário de convivência e o futuro como construção ou criação figuram como objetivo e slogan desejável para a humanidade. A dificuldade reside na forma e no sentido que iremos dar a tal articulação. Hoje, a direção do tempo nos remete ao futuro como alguma coisa para inventar, justo no momento em que, por um lado, se abrem as expectativas e, por outro, as feridas da história vigentes no tempo presente, então submetido a todo tipo de incertezas.

A situação, em geral, não é nova. Vale a pena lembrar a obra do filósofo Ernst Bloch O Princípio da Esperança, escrito precisamente em um período de máxima turbulência, medo e horror entre 1938 e 1947, quando o mundo conheceu também pela primeira vez, a possibilidade técnica de autodestruição. Este começou seu livro com as seguintes perguntas: Quem somos? De onde viemos? Para onde vamos? Que esperamos? O que nos espera? (BLOCH, 1977,

\footnotetext{
1 Professor da Universidade do País Basco (UPV/EHU). Departamento de Didática das Ciências Sociais

2 Disponível em: http://www.ub.edu/histodidactica/images/documentos/pdf/lopez_atxurra.pdf

3 Universidade Estadual de Londrina.
} 
p. XI) ${ }^{4}$ Estas questões continuam centrais para a atenção dos seres humanos em geral, e dos historiadores e professores em particular. Pode-se dizer que a partir das atitudes e respostas sobre estas questões vão se formando nossos comportamentos e modos de convivência, bem como as nossas preocupações sobre a construção e transmissão do conhecimento.

Ao longo deste texto, primeiro, tentarei mostrar brevemente que tipo de cidadania procurava promover o ensino da história tradicional. Seguidamente, com foco no mundo atual, vou desenvolver de modo mais detalhado algumas questões e problemas colocados pelo ensino da história a partir da perspectiva de uma educação para a cidadania. Para isso, tratarei essas perguntas e problemas a partir da perspectiva de quatro eixos envolvidos neste processo: o poder, os historiadores, os professores e os estudantes.

\section{Ensino da História: para que tipo de cidadania? Antecedentes}

A primeira questão a ser abordada diz respeito ao papel desempenhado no ensino de história na formação de cidadãos. Na sociedade tradicional, o indivíduo vivia, em geral, em lugares próximos e tinha laços familiares e de vizinhança estruturados em torno de hábitos, costumes e rituais transmitidos oralmente. Mitos, histórias de família e celebrações religiosas fundamentavam uma mentalidade e davam coesão ao grupo.

O século XIX expande e muda os horizontes das pessoas: do campo para a cidade, do trabalho doméstico à fábrica, do vínculo familiar ao Estado-Nação, da transmissão oral à transmissão institucional escolar.

Frente às experiências de vida na terra natal, na casa ou na família surgem para as pessoas deste século, novos cenários abstratos como o EstadoNação com o qual se criam vínculos jurídicos e burocráticos. Esta nova estrutura de convivência, o Estado-Nação tentará fazer da escola, com variados graus de sucesso, um instrumento chave da coesão nacional. Para isso, contribuirá através da história com novos relatos significativos que substituam aos do

\footnotetext{
${ }^{4}$ Bloch escreveu este livro durante seu exílio nos Estados Unidos e revisado em 1953 e 1959, já na República Democrática Alemã.
} 
ambiente familiar. Era crucial apresentar, por um lado, os grandes heróis (reis, cavaleiros, militares... $)^{5}$ representados como modelos ideais e, por outro lado, fatos vinculados a ações heroicas de caráter bélico (Numancia), para que a história pudesse apresentar e construir o orgulho de pertencer a um EstadoNação.

O Estado-Nação é apresentado ao aluno como o único espaço de referência, então ampliado em alguns momentos de extensão de territórios imperiais. Este espaço se apresenta como um todo homogêneo, cujo destino está marcado nos primeiros tempos históricos. Assim se ocultam outras realidades sociais e institucionais como também os processos históricos discordantes. Esta ênfase na história do Estado-Nação faz com que a mesma se apresente, na maioria dos casos, desligada da História Universal. Os outros países aparecem como amigos ou inimigos, sob uma visão maniqueísta também em relação a personagens, aos grupos e às ideias.

O ensino da História tem estado ao serviço da construção de uma identidade e consciência nacional. No entanto, a sua introdução como disciplina escolar é desigual, conforme as etapas educativas e de acordo com os países. Em princípio, é uma matéria mais relacionada à educação vinculada à formação de ideais da juventude. Assim, na França, a história é obrigatória a partir das primeiras décadas do século XIX (1818) por impulso dos constitucionalistas $\left(\right.$ PROST, 2001) ${ }^{6}$. A instrução sobre a formação histórica no quadro social e político do qual fará parte a elite dos novos cidadãos é fundamental para a formação nos ideais patrióticos e republicanos ${ }^{7}$. Na Espanha, se introduz o ensino da História e Geografia - "especialmente da Espanha" - no programa das escolas primárias superiores ${ }^{8}$ em meados do século $\mathrm{XIX}^{9}$.

\footnotetext{
${ }^{5}$ Como Indíbil e Mandonio, Viriato, El Cid, Guzmán o Bom, os Reyes Católicos...

${ }^{6}$ Sobre este tipo de impulso, ver página 33. Sobre o processo de introdução, ver páginas 29-34.

7 "Os partidários da história assumem uma posição política". "A história francesa deveria esclarecer o desenvolvimento geral das instituições da sociedade moderna: deve inspirar respeito e compromisso com os princípios sobre os quais esta sociedade foi fundada". Esta citação é de Gerbod (1880), e aparece em PROST (2001, p. 34).

8 Este tipo de escola não é obrigatório e está reservada a crianças de mais de doze anos. A introdução dessas matérias está regulada no artigo $4^{\circ}$ da Lei geral de introdução pública, de 9 de setembro de 1857. (ALTAMIRA, 1934, p. 37).

9 "No período 1841-1868, se forja e se reforça a tradição dos livros didáticos de História". (CUESTA FERNÁNDEZ, 1998, p.29)
} 
Pelo contrário, a história é mais tardiamente introduzida como disciplina obrigatória na escola primária, a partir da década dos sessenta do século XIX na França $^{10}$ e inícios do século XX (1901), na Espanha ${ }^{11}$. Também não faltaram, no caso da França, tentativas de incorporar o ensino da história à educação préescolar com apoio de "anedotas, relatos (e) biografias extraídos da história nacional"12. No caso espanhol, o ensino de história na escola primária não teve originalmente, do ponto de vista legal, um caráter nacionalizador, já que da matéria de "Geografia e História" é removida a expressão "especialmente da Espanha". Assim, de acordo com Altamira: "esta nova redação parecia dar aos professores uma possibilidade mais ampla de conceber o ensino de História a partir de um ponto de vista que não fosse o da história estritamente nacional" (ALTAMIRA, 1934, p. 38) ${ }^{13}$, abrindo espaço para outras histórias e outras metodologias. No entanto, a prática pedagógica dos professores e os livros didáticos de referência se restringiam ao ensino da História nacional (ALTAMIRA, 1934, p. 39-40).

Para uma criança que só conhece a experiência familiar imediata, a nação é uma abstração. Portanto, era necessário inculcar uma nova percepção, mais apreensível, a existência de uma entidade protetora, a mãe-pátria. Não bastava a memorização de informações áridas, era necessário trabalhar a parte emocional, porque "o amor à pátria não se aprende de cor, aprende-se com o coração" (LAVISSE apud PROST, 2001, p. 39). Assim, recorre-se aos formatos de apresentação de conteúdos mais concretos e vivenciais como a imagem, o relato e a lenda.

Emoções e sentimentos estão associados aos textos, às imagens e aos títulos das lições. Os manuais também reúnem a influência das várias ideologias

10 Em 1867 se adota como matéria obrigatória. Em 1880 entra na "prova oral de certificado de estudos". Em 1882 se estabelece definitivamente nos horários (duas horas semanais) e nos programas. Em 1890 se adota a obrigatoriedade do manual. (PROST, 2001, p.38-39)

${ }^{11} \mathrm{Um}$ decreto real estabelece a lista de matérias comuns às escolas elementares e superiores. $\mathrm{O}$ artigo $3^{\circ}$ do decreto de 1901 inclui na lista o assunto "Geografia e História". (ALTAMIRA, 1934, p. 38). É necessário recordar que antes dessa data a história que estudavam as crianças era história sagrada.

12 Em 1880, se questionava institucionalmente este modelo de ensino. Não obstante, a história e a geografia se mantiveram no pré-escolar até começos do século XX. (PROST, 2001, p.40)

13 Durante as três primeiras décadas do século $X X$, os livros que se dirigem à infância são mais patrióticos que aqueles que se publicam para outras etapas educativas. Altamira assinala que "os livros didáticos espanhóis são moderados". O autor faz menção, inclusive, a um livro patriótico que fracassou completamente. (ALTAMIRA, 1934, p. 46-47). 
presentes na sociedade ou refletem a evolução das ideologias dominantes. Não há a mesma intenção da lição intitulada "Cooperação e Solidariedade" do texto de Gonzalez Linacero (1933) que coloca a ênfase nos valores sociais e na identidade comum do gênero humano, com aquelas intituladas "Mouros e Cristãos", "Coisas de mouros", "A lutar" de Agustin Serrano de Haro (1962), ou ainda "Fora o liberalismo, tradição em pé" de Gurpide que enfatizam valores como o belicismo, a xenofobia e a intolerância.

Consequentemente, a identidade pode-se construir ao redor de múltiplos referentes. Em princípio, trabalhar a identidade do gênero humano e o sujeito histórico como um ser social tem sido uma exceção. Esta perspectiva educativa baseia-se em uma orientação para a cidadania no ensino da história, da qual "se espera... que desperte no aluno o sentido social, o sentido da vida em sociedade e dando-Ihe conhecimento dos principais acontecimentos históricos, que Ihe iniciem no pensamento político" (RENAN apud MUSEO PEDAGÓGICO NACIONAL, 1934 , p. 16). Para se integrar na sociedade desta forma, fundamental seria fornecer as ferramentas necessárias para conhecê-la e de capacitar para pensar socialmente. Assim, para enfatizar o valor da história, Halbwachs (1925), disse que "há muito poucas noções gerais que não apresentem para a sociedade a oportunidade de se relacionar com um determinado período de sua história. Isso é evidente quando se trata, para ela, de conhecer-se, refletir sobre suas instituições e sua estrutura, sobre suas leis e costumes" (HALBWACHS, 2004, p. 328). Portanto, o conhecimento de noções sociais com toda a sua gênese histórica não tem uma função erudita, mas neste caso o ensino da história tem uma orientação pragmática como seu principal objetivo, como tem sido a tradição americana do início do século XX: "aprender a viver feliz em comunidade" (MUSEO PEDAGÓGICO NACIONAL, 1934, p. 16). Supõe-se que "mostrando ao aluno a origem das questões que irá enfrentar como membro de uma sociedade, como cidadão, a História irá colocá-lo em condições de formar parte da vida política do seu país" (MUSEO PEDAGÓGICO NACIONAL, 1934, p. 16).

Em contraste com o exposto anteriormente, o usual tem sido inculcar uma identidade nacional homogênea através do ensino da história. No entanto, essa identidade nacional pode adquirir diferentes cores ideológicas. Já mencionamos a 
identidade nacional baseada em ideais patrióticos republicanos que enfatiza a consciência política através da aquisição de noções como lei, democracia, estado de direito, direitos do cidadão, que foram construídos historicamente. Por outro lado, a identidade nacional, no caso da Espanha, em geral, não teve esse sentido de interesse pela república, mas recorreu para figuras e fatos que representam a essência da Pátria. Desta maneira, tenta-se transmitir valores morais conservadores, que exaltam a tradição e que no seu auge se reflete no nacionalcatolicismo. Nesta linha, Serrano de Haro dirá: "Queremos que comecem a ouvir os nomes exemplares e atos heróicos, que as coisas de Deus e da Espanha entrem como sal abençoado, no fermento germinal da sua consciência" (SERRANO HARO, 1962, p. 07).

O ensino de História que conhecemos predominou durante grande parte do século XX na Espanha e não está inserido nos parâmetros de cidadania laica e republicana, mas deve-se lembrar de que houve seguidores desta linha. Sim, persistem as concepções cristãs da história, as quais se refletem a partir das primeiras páginas dos livros didáticos, fundamentado na visão criacionista ${ }^{14}$, no cruzamento da história sagrada com a utilidade moral ${ }^{15}$.

Dentro desta linha, o propósito do ensino da história não é construir cidadania, e sim, a educação moral maniqueísta ${ }^{16}$. Assim, no auge da ditadura franquista, pretende-se a formação do caráter através da aprendizagem do medo, do ódio, do ressentimento em relação aos inimigos internos e externos da pátria, acompanhada pela transmissão de valores como a coragem, o martírio e o sacrifício. Desde essa perspectiva autoritária, a liberdade, a constituição, a

\footnotetext{
${ }^{14}$ Ainda nos anos trinta se mantém tal visão. Uma lição de História começa desse modo: "Há milhões de anos atrás, existiu Adão e Eva, isto é, havia gente na terra", A lição de História Sagrada: "Deus criou o mundo em seis dias". (PORCEL; RIEVA, 1937, p.131).

15 "A história tem utilidade? - Sim senhor, porque forma o coração do homem,, fazendo-lhe amar a virtude e dar exemplo de boas ações, evitando o vício e seus desdobramentos nefastos". (MARTINEZ ABELLAN, 1903, p.5). Em destaque o autor traz ainda uma citação de Cardería: "A História, por sua própria natureza, serve admiravelmente para formar o homem religioso e moral, o homem inteligente o homem físico e social". (CADERIA apud MARTINEZ ABELLAN, 1903, p.5). Nos informes do entre guerras (anos 30), recolhidos no livro publicado pelo Museu Pedagógico Nacional se nota que no conjunto europeu existem poucos que se preocupam com o ensino moral com a ajuda da história "Uma grande maioria parece considerar, sem dúvida com razão, que esta questão não está entre o rol de preocupações do professor de história" (MARTINEZ ABELLAN, 1903, p.15).

16 "Nunca falta, enfim, o propósito da educação moral. A alma dessas crianças tem uma plasticidade incrível para agarrar-se aos grandes exemplos (...) melhor aproveitar o momento, antes de este passe, e que a história em suas mãos (...) é o cadinho para fundir o caráter da geração que a Pátria nos dá para formar" (SERRANO DE HARO, 1962, p. 5-6)
} 
democracia, os partidos, os políticos são equivalentes ao caos. O medo da liberdade é resolvido por meio da submissão e do culto ao líder. Nesta linha, os primeiros parágrafos da lição 31 de Serrano de Haro não poderiam ser mais explícitos: "Franco é o líder da Espanha: Ele manda e nós obedecemos" (SERRANO DE HARO, 1962, p. 88). Como pode observar-se, a frase é curta, redigida como um lema para que a ideia básica seja facilmente interiorizada. 0 objetivo da aula não é apenas cognitivo, aprender a regra básica de funcionamento da ditadura, mas também afetivo, pois, considera em nota a orientação pedagógica da lição: "obviamente o propósito desta lição não será alcançado até os pequenos entusiasmarem com Franco" (SERRANO DE HARO, 1962, p. 90).

A exposição precedente nos mostra no conjunto como a instrução na Espanha tem-se orientado nas décadas centrais do século $X X$ para a promoção dos ideais fascistas e deveres patrióticos, que se centram fundamentalmente na defesa da pátria. Em períodos autoritários ou de crise internacional a história bélica e maniqueísta era transmitida nas escolas, e destinou-se à formação de crianças com mentalidade de soldado. Esta tradição não é exclusiva da Espanha, já que também observamos na França uma longa tradição durante os séculos XIX e XX em torno da instrução escolar de cidadãos-soldados (INRP, jul. 1988/jun. 1989). Assim, houve pensadores e educadores que têm visto neste belicismo presente nos livros didáticos uma das causas da primeira disputa mundial (JARES, 1991, p. 31). Por outro lado, na década de oitenta, modifica-se na Espanha o modelo temático e a guerra desaparece quase por completo dos livros didáticos, o que significa, "perder a oportunidade... de atuar na educação dos valores" (BASTIDA, 1994, p. 15) ${ }^{17}$.

Em síntese, o modelo de cidadania proporcionado pelo ensino tradicional da história foi construído em torno da primazia destes elementos:

- Socialização passiva

- Aprendizagem para conservar a herança cultural

- Promoção da identidade nacional

17 Sobre a ausência da guerra nos textos, ver páginas 15-26. Sobre as razões pelas quais se deveria ensinar a guerra, ver páginas 41-79. 
- Pensamento conservador

- Manutenção da ordem estabelecida

\section{Ensino de História e Educação para a Cidadania: perguntas e problemas A perspectiva de poder: a preocupação identitária}

A partir dessa perspectiva, o ensino da história tem sido usado para construir um sentido de grupo, um "nós" (PAGES, 2005, p. 46) ${ }^{18}$ homogéneo ${ }^{19}$, e para orientar "a fidelidade a um tipo de Estado" (ARTOLA apud ORTIZ DE ORRUÑO, 1998, p. 122). Hoje em dia, permanece essa preocupação identitária e, em alguns meios de comunicação, se nota a preocupação com a presença ou a ausência da história nos currículos e o que isso pode influenciar no futuro dos Estados-Nação ${ }^{20}$. O ideal e o ser nacional das pessoas estariam alimentados hipoteticamente pelo conhecimento histórico. No entanto, a realidade é mais complexa, uma vez que, por um lado, nos mostra que a construção de tal concepção pode "utilizar-se de outros meios", e, por outro lado, nos revela que o ensino da história não garante a "identidade buscada" (PROST, 2001, p. 27$28)^{21}$.

Apesar de tudo, em nosso entorno cultural, tradicionalmente, este "nós" homogêneo foi construído nas narrativas históricas escolares a partir de uma perspectiva essencialista e maniqueísta ${ }^{22}$, ocultando a heterogeneidade social, as

18 Essa expressão é de Mesnard, e colhida por Pages.

19 "Homogeneizar as sociedades em torno da cultura comum (...) por meio do ensino da história" (JELIN; LORENZ, 2004, p. 2-3).

20 "A ignorância sobre a história da América e sobre o civismo debilitam nosso sentido de cidadania. Ser um americano não é uma questão apenas de sangue ou de nascimento; estamos envoltos em ideias, e nossas crianças devem saber de tais ideais" (Discurso do presidente G. Bush, 2002). (PAGES, 2005, p. 47). No caso da França, o presidente Miterrand declarou em um conselho ministerial em 1982 que "um povo que não ensina história é um povo que perde sua identidade" (PROST, 2001, p.27). É interessante recordar nesse sentido, na Espanha, o debate em torno da história nos finais dos anos 90 do século passado. (ORTIZ DE ORRUÑO, 1998).

${ }^{21}$ Este autor nota países nos quais o ensino da história não teve peso se não em etapas educativas superiores. Também faz menção ao caso da Argélia, a que poderíamos adicionar, no caso da Espanha, os grupos que se auto-identificam com seus respectivos nacionalismos periféricos.

22 "A Espanha é muito formosa. Na Espanha existem serras muito altas e rios muito largas e muitas fontes e muitas flores. E os campos dão trigo e azeite de oliva, vinho e mel. E o sol é muito brilhante e o céu muito azul. Então, todos os homens queriam viver na Espanha. (...) alguns dos que vieram eram muito ambiciosos e queriam expulsar os espanhóis e dominar o povo, ficar com os campos e as riquezas da Espanha, mas os espanhóis não consentiram e aventuraram-se no outro lado do mar." (SERRANO DE HARO, 1962, p.16-17). 
relações fluídas e interdependentes entre o interno e o externo, e a contribuição dos "outros" no processo de formação de um "nós" plural e diverso ${ }^{23}$.

Diante da evidência deste "nós" plural, hoje podemos fazer certas perguntas, quer deveriam questionar nossas pressupostos. Em um mundo tão fluido como o presente, qual é o ideal e o ser que dá corpo ao cidadão de um país, seja ele americano, francês, espanhol, basco ${ }^{24}$ Existe decerto uma resposta única? ${ }^{25} \mathrm{Em}$ princípio, os quadros identitários de referência são múltiplos (ecológicos, materiais e psicológicos, históricos, culturais, psicossociais), enquanto a lista de referências concretas para cada um desses quadros se nutre das preocupações de um conjunto heterogêneo de ciências sociais e humanas (sociologia, psicologia social, etnologia, demografia, história, geografia, ciência política). De tudo isso resulta percepções ou abordagens parciais para um conceito de identidade abstrato e complexo. Tomar como realidade objetiva uma identidade total nos levaria a uma identidade virtual inexistente (MUCHIELLI, 2006, p. 12-18). Em vez disso, a identidade é uma construção relacional não isenta de dificuldades ${ }^{26}$ que "aparece em cada indivíduo como uma combinação singular e variável" (DEL OMO PINTADO; HERNANDEZ SANCHEZ, 2006, p. 9) ${ }^{27}$.

Consequentemente, dada a crescente variedade na composição humana das nossas aulas, que oportunidades o currículo e os textos didáticos de história oferecem para que todos os alunos se reconheçam? É uma história inclusiva ou

23 Uma reflexão interessante sobre a presença dos outros na história, ver: OLLER I FREIXA, Montserrat, PAGES I BLANCH, Joan. La historia de los otros. Historiar, no 3 (Octubre, 1999), p.172-187. Ver também: NAVARRO, Joseph (org.). El islam en las aulas. Icaria, Barcelona, 1997; MORENO, A. El arquetipo viril protagonista de la historia. Ejercicios de lectura no androcéntrica, La Sal. Ediciones de les dones, Barcelona, 1986.

24 "A chave para a sobrevivência das liberdades no mundo atual é assumir as múltiplas identidades (...) Todo britânico é ao mesmo tempo algo mais (...) A Grã-Bretanha é peculiar, impossível de teorizar e confusa na prática, mas magnífica: quatro nações em uma. Para expressar quem somos, devemos exibir muitas bandeiras e não centrar em uma" (GARTON ASH, n. 22, jan/2006, p. 11).

25 Sobre os exames de cidadania nos EUA, Holanda e Alemanha para imigrantes, ver: El País, n.18, mar/2006, p. 4.

26 Sobre os modos de vida do indivíduo contemporâneo, Peter Berger y Brigitte Berger percebem: "Distintos setores da vida cotidiana os colocam em relação a mundos de significação e experiência muito distinto e discrepante. A vida moderna está segmentada a um grau de segmentação (ou pluralização...) que não se manifesta somente ao nível da conduta social observável, mas também em manifestações do nível da consciência" (BERGER; BERGER, 1979, p.64)

27 A partir da perspectiva da personalidade individual, Hilda Taba nota que: "Todo homem é em certos aspectos: a) como todos os homens; b) como alguns outros homens; c) como nenhum outro homem" (TABA, 1974, p. 77). 
exclusiva ${ }^{28}$ Ajuda a história escolar a construir a identidade pessoal e social dos alunos para além da identidade nacional? Quais são as idéias básicas que devem ser consideradas objetos de consenso ${ }^{29}$

Por outro lado, como se levanta a apropriação de um "nós" configurado por um passado vergonhoso ${ }^{30}$ É uma história ausente, uma história que se justifica ou dá margem para a autocrítica? Como deve ser assumido esse passado vergonhoso para os novos cidadãos ${ }^{31}$

\section{A perspectiva dos historiadores: as funções do conhecimento}

A partir dessa perspectiva, o conhecimento histórico tem sido uma maneira de tomar autoconsciência social. Nas palavras de Raymond Aron "foi e ainda segue sendo uma forma da sociedade conhecer a si mesma, seja por meio da comparação com outras sociedades, seja pela reconstituição de suas origens e de seu futuro" (ARON, 1996, p. 400).

Desvelar o oculto no passado, iluminar a realidade atual, dar pistas para seu funcionamento evolutivo tem sido parte da tradição iluminista que nos tem acompanhado durante os dois últimos séculos. Paradoxalmente, a confiança no poder do conhecimento científico e dos meios de comunicação levou a uma sociedade acostumada a pensar que a realidade é transparente e "a acreditar em tudo o que se vê". Por outro lado, hoje em dia, as dificuldades do ato de conhecer são cada vez maiores. O homo videns da sociedade teledirigida se encontra com uma sobressaturação de imagens, além de sofre com processos de sub-informação, desinformação ou pseudo-informação que anulam os conceitos, o pensamento abstrato e favorece "o empobrecimento da capacidade de entender" a realidade (SARTORI, 2001, p. 83-91) ${ }^{32}$. Por outro lado, comportamento como o zapping, o culto ao efêmero, o acesso a multicanais e o uso de um heterogêneo mundo de janelas fragmenta a realidade em uma

\footnotetext{
28 Perguntas extraídas da de Caridad Hernandez e Margarita del Olmo (2006, p. 19).

29 Pensa-se nas diferentes concepções sobre Espanha às quais trabalhou a historiografia: Espanha eterna, nação das nações, nação em processo de construção.

30 A questão da apropriação de um passado vergonhoso e levantado por GELERMAN é citado por Elizabeth Jelin e Freerico Lorenz (JELIN; LORENZ, 2004, p. 5). A obra coordenada por esses autores tem como eixo que, na relação entre educação e memória, se encontra a raiz do trauma produzido pelas ditaduras latino-americanas.

31 Sobre a forma como se entende e se percebe o ensino de história sobre o nazismo na Alemanha, ver o sugestivo trabalho de, Bodo Von Borries (2006, p. 64-79).

32 Sobre o empobrecimento da capacidade de entender, ver páginas 49-52.
} 
infinidade de microcosmos visuais e vitais, dificultando talvez uma visão mais significativa. Também se observa que a crescente complexidade do mundo contemporâneo aumenta a opacidade, uma vez que "a explosão do pluralismo e a diversificação dos meios de vida conduz a um mundo mais enigmático, heterogêneo e difícil de compreender" (INNERARITY, 2004, p. 54) ${ }^{33}$.

Pensar social e historicamente envolve também dar pistas para sua operação evolutiva. No entanto, "reconstituir o futuro" é problemático, porque, uma vez perdida a esperança nas grandes filosofias da história (salvação cristã, a sociedade sem classes marxista...) ${ }^{34}$, paradoxalmente, o progresso nos levou a um futuro incerto e de risco ante o qual se manifestam múltiplas microalternativas. Estamos diante de uma "crise de representação... que nos priva de sistemas de orientação que permitiriam delinear a realidade e reduzi-la a um tamanho mais manejável" (INNERARITY, 2004, p. 55).

Também no "fazer" cotidiano do historiador diminuíram as "grandes interpretações de conjunto". Em vez disso, eles valorizam agora as "verdades parciais e provisórias", de modo que há "uma dobra sobre temas que combinam história das representações e micro-história". Segundo Prost, "trata-se de decifrar as sociedades de outra forma..." (PROST, 2001, p. 282). A atitude do historiador é menos transcendental e mais realista, já que sua indagação se orienta pela "preocupação com as verificações, o culto à precisão e à informação completa" (PROST, 2001, p. 282).

Em um mundo no qual se maquiam as provas e se distorcem os dados não é de todo mal levantar essas preocupações profissionais como atitudes básicas para o exercício do pensamento crítico e de uma ação cidadã. Assim, o método histórico nos coloca em relação com a função cívica do conhecimento.

Por último, depois de um trabalho árduo, o historiador se limita a afirmar que "nós não sabemos para onde vamos, mas apenas que a história nos trouxe

\footnotetext{
33 "Temos a impressão que o poder está à vista, mas ao mesmo tempo, os poderes que nos determinam são cada vez mais invisíveis e menos identificáveis" (INNERARITY, 2004, p. 52).

34 Gianni Vattimo notava alguns anos antes da queda do muro de Berlim que "carecemos de uma representação comum e aceita sobre a ideia de progresso (...). Entretanto, também indicava que "as grandes narrativas legitimadas, a filosofia da história, não desapareceram por completo (...) tornam-se problemáticas, mas constituem ainda o único conteúdo de nosso pensamento e cultura" VATTIMO, 1986, p. 12-13).
} 
até este ponto" (HOBSBAWM, 1995, p. 576) ${ }^{35}$. A história apresenta não só as experiências e os erros do passado, mas também ajuda a identificar os problemas do presente. Este é o material a partir do qual os cidadãos devem escolher e tomar decisões sobre os novos pactos de cidadania, cujos objetivos serão abrir o horizonte de possibilidades, a fim de evitar o colapso, e criar sociedades alternativas (DIAMOND, 2006).

\section{A perspectiva dos professores: tipologias e práticas plurais}

A perspectiva dos professores sobre o ensino da história a partir de um enfoque (da educação) para a cidadania está determinada por um conjunto de fatores que incidem em sua prática docente.

Primeiro, encontramos o tipo de socialização político-social que estes professores experimentaram em função do período ou períodos históricos em que viveram (ditadura, transição ou democracia) ${ }^{36}$. A experiência social e a cultura política adquirida intervêm na formação da sua personalidade, na estrutura e na evolução do seu pensamento cívico e em seu nível cultural. Aqui, toma corpo as concepções que vão construir e modificar a identidade, o valor do passado, as expectativas o sobre o futuro, as noções de política e de democracia, as ideias sobre resolução de conflitos, o papel das instituições, avaliação a valorização e atitudes em relação ao "outro" 37 e muitos mais. Além disso, o grau de vinculação, filiação ou transformação ideológica, bem como os hábitos sociais de inibição ou participação social irão intervém no conjunto de preocupações, interrogações, ideias e proposições sobre a vida social.

Caberia perguntar quantos tipos de professor surgem a partir destes contextos e como eles afetam o processo de transmissão-aquisição de conhecimentos, atitudes, hábitos e valores de cidadania. Por exemplo, na seleção

\footnotetext{
${ }^{35}$ A frase continua da seguinte forma: "E, se os leitores partilham a abordagem deste livro, e por que".

36 Um grupo numeroso de professores de história em exercício no começo do século XXI desenvolveu a vida acadêmica, assim como os primeiros anos da docência em meio a transição do franquismo, sofrendo os resultados do governo ditador de Franco. A idade média atual destes professores é de 47 anos e possuem 20 anos de experiência. Parte destes professores tem uma participação ativa na transição política (MERCHAN, 2005, p. 15-16).

37 Sobre as atitudes perante o "outro" ver: VALLS, Rafael, Multiculturalidad y prácticas pedagógicas. El multiculturales: diversidad e identidad, XIII Congresso Nacional y Iberoamericano de Pedagogía, Valencia, 2004, p.169-181. Este autor recorre ao trabalho coletivo IOEE (1999) onde são especificadas cinco atitudes da comunidade educativa perante "os diferentes culturalmente" que parte da rejeição ao diferente para a educação antirracista.
} 
dos temas, no grau de profundidade e interesse que se aplica, nos objetivos propostos, nas formas de trabalho que o motivam, etc. As imagens transmitidas sobre o passado $^{38}$ às atitudes em relação ao presente e ao futuro, não estão à margem de sua biografia. Assim, Manuel Cruz nos diz que "a melancolia com a qual o homem adulto vive a frustração de suas ambições juvenis não constitui uma boa figura para pensar a história: nem mesmo nos permite reconstruir verdadeiramente a experiência da ilusão pelo futuro coletivo que outrora já tivemos" (CRUZ, 2005, p. 220). Portanto, é necessário ter em conta a incidência docente que pode ter a vivência do passado, do presente e das expectativas de futuro que os professores possuem como cidadãos.

Em segundo lugar, a noção dos professores sobre história e ensino de história, assim como sua prática se relaciona também com a sua socialização profissional e concepções epistemológicas sobre o conhecimento. Ideias sobre como entender o conhecimento podem variar de acordo com as experiências acadêmicas ou modelos dominantes de conhecimento. Simplificando muito, pode-se guiar por concepções dogmáticas deterministas que apontam para uma interpretação linear e consideram a história ou as ciências sociais como um sistema fechado em verdades absolutas. Neste caso, a busca de certezas objetivas reside, sobre tudo, no apelo a textos com autoridade que dão suporte a esquemas interpretativos de explicação geral ${ }^{39}$. Outras, pelo contrário, apresentam uma concepção aberta na qual o conhecimento está submetido a um processo de reflexão, onde a reconstrução dos fatos promove interpretações divergentes, as verdades são provisórias e parciais, ainda admitem lacunas, insuficiências e incertezas do conhecimento (WALLERSTEIN' 2005). Esta outra concepção, não só oferece maneiras diferentes de entender e construir o mundo,

38 Rocío Trinidad se pergunta "acerca das memórias que se encontram vigentes no professorado" (TRINIDAD, 2004, p. 11). Entre as questões levantadas, encontramos: "Interfere a socialização dos docentes e a construção de memórias do passado? Se é assim, que mem[orias transmitem? Existem elementos que condicionam a transmissão das memórias? Quais mudanças, rupturas, continuidades se produzem?" (TRINIDAD, 2004, p.12).

39 Rocío Trinidad, por exemplo, se refere aos jovens universitários e professores influenciados pela doutrina sanderista. Na universidade europeia e espanhola dos anos setenta também se pode falar da influência do marxismo. É necessário verificar no futuro o impacto de outros dogmatismos como os fundamentalismos de distintos signos, herdeiros do tradicional providencialismo. Ver atualmente a influência do criacionismo (reformulado como teoria do desenho inteligente) no ensino da história de muitas escolas dos Estados Unidos. Percebe-se a concepção relativista do "tudo vale" ou a concepção niilista do "nada vale". (TRINIDAD, 2004, p. 16) 
mas também pode promover capacidades e diferentes atitudes quanto à cidadania.

Em terceiro lugar, devemos considerar as concepções epistemológicas que os professores possuem sobre a educação. A princípio parece plausível que os professores podem estar fortemente influenciados por dois fatores que descrevemos até o momento, mas tampouco se pode esquecer que as teorias educativas que têm como referência, sobretudo, as experiências e vivências de sala de aula têm servido de modelo ao longo de sua trajetória.

Cabe perguntar quais motivações e atitudes impulsionam a prática pedagógica do professor: são valores sociais e políticos? Quais? Ou, ao contrário, é a sua própria vivência pessoal que prevalece em sala de aula? Este professor dá mais relevância à instrução ou a educação? Como encara a relação entre instruir e educar? Qual a concepção sobre seu trabalho? Pensa que seria uma tarefa centrada somente na figura do professor e em aulas expositivas? Ou que seria uma tarefa de equipe, interativa? Seria uma tarefa que exige um esforço comunitário? Entende seu trabalho de uma forma hierárquica onde a palavra do professor é única e que não permite interações ou, pelo contrário, favorece a interação em sua aula através de tarefas de reflexão e cooperação? Em suma, o fato das práticas escolares estarem orientadas por uma ou outra concepção não é desprezável, uma vez que a partir delas pode-se desenvolver uma educação voltada para uma cidadania de alcance diferente.

Por outro lado, também é relevante como se percebe o currículo oficial. Como um programa rígido que deve se aplicar sem fugir do que este propõe; como uma pauta de orientação para se trabalhar, o qual se outorga autonomia e capacidade de adaptação às circunstâncias concretas de seu meio; ou, por último, como algo que se deva contrapor.

Também atitude do professor frente ao processo de transmissão-aquisição do conhecimento pode ser pensada de diferentes formas: orientando-se a partir das exposições de informações históricas ou impulsionando a aprendizagem através de métodos que permitam o acesso e a construção de conhecimentos. Ainda podem centrar seu compromisso na divulgação de um saber histórico elaborado a partir de uma única posição de um observador neutro que se prima na afirmação de fatos e que não deixam nenhuma margem de intervenção do 
aluno. Além desta concepção linear e fechada, seu compromisso pode se orientar para oferecer não somente fatos e processos, mas também, todo um conjunto de marcos interpretativos e sucessivas revisões historiográficas, esclarecendo o porquê das mesmas revisões. Neste caso, adquire-se maior relevância a possibilidade de oferecer uma visão mais dinâmica e aberta do saber, mediante a apresentação dos problemas históricos e das reflexões divergentes que os suscitaram. Podemos concluir, aqui, que o interesse vai mais além de informações eruditas, já que se pretende familiarizar o aluno com os modelos do pensamento histórico.

Em uma abordagem da educação voltada para cidadania, o ensino de história deve adquirir um significado diferente da ideia teórica de que "tem que ser objetivo" ${ }^{40}$ mediante a uma descrição linear, pelo contrário, pode-se oferecer aos alunos recursos cognitivos e procedimentos que permitam acesso ao conhecimento de forma que estes consigam problematizar as questões. Assim, oferecer um conhecimento já elaborado e fechado não é o mesmo que gerar situações de aprendizagem com objetivo de facilitar contextos individuais ou grupais de forma que o aluno aprenda pensar e avaliar a realidade histórica. Do ponto de vista da cidadania, não se deve apresentar a história do passado como uma descrição de compartimentos estáticos, mas buscar nexos e diferenças entre o passado e o presente de modo a abordar os problemas e as expectativas da comunidade humana. Por último, as atitudes geradas em torno do papel do sujeito na evolução histórica podem adquirir significados diferentes se nos pautarmos na exposição de um único sentido oculto ou explícito, de caráter unidirecional que marcará a orientação para o futuro ou, pelo contrário, podemos apresentar a história do passado submetida não somente a fatores estruturais, mas na concorrência dos diferentes atores sociais que estão em um jogo aberto e apresentam múltiplos finais.

Do exposto resulta que, a partir da perspectiva de educação para cidadania, a tipologia quanto aos professores de história, assim como em relação

\footnotetext{
40 "É comum a noção do docente de que 'precisa ser objetivo' e que isso implica 'não simplificar', coexistindo com o fato de que o docente acaba sempre simplificando. Dessa combinação surge a percepção do docente de que 'o que digo é certo' porque 'sei dos livros'. Por isso, em geral, o docente é absoluto, porque internaliza esta prática e porque seu trabalho só é avaliado por ele mesmo". (LORENZ apud JELIN; LORENZ, 2004, p. 172).
} 
à sua prática pedagógica, podem ser muito heterogêneas (EVANS, 1991) ${ }^{41}$. Junto ao seu papel de transmissor de um saber próprio, profissional, concilia-se seu saber de cidadão portador de uma história presente. Podemos em um primeiro caso, falar daqueles que orientam sua docência a uma transmissão do conhecimento dos historiadores, enquanto que, no segundo caso, encontramos, uma parte daqueles que outorgam um papel da transmissão de suas próprias vivências ${ }^{42}$ e, ainda por outro lado, aqueles que tomados por medo ou outros sentimentos (vergonha, culpa, rejeição...) silenciam fatos, omitem interpretações divergentes, ou ocultam sistematicamente etapas históricas ${ }^{43}$. Nesta linha, não devemos esquecer as atitudes de resistência ao lidar com temas sociais espinhosos e problemáticos ${ }^{44}$. Finalmente, cabe ressaltar que o trabalho do professor não ocorre isoladamente, mas no quadro de uma instituição escolar onde se enfrentará, por um lado, colegas que compartilharão da mesma opinião ou entrarão em divergência e, por outro, com a comunidade de pais e outros grupos que agem sobre a comunidade escolar. Portanto, sua prática pedagógica não estará livre de conformismo, compromisso ou rebeldia com o estabelecido e dominante de cada meio.

\section{A perspectiva dos alunos: cidadanias emergentes}

Estes horizontes de atuação profissional podem influenciar na educação dos alunos, favorecendo ou dificultando um clima democrático de aula que impulsione comportamentos pautados na cidadania e na confiança na construção de um futuro melhor. Entretanto, esta tarefa não pode ser compreendida em sua complexidade se esquecermos das características destes novos cidadãos com os quais o professor deverá interagir. Os alunos não são recipientes vazios a serem

41 Este autor estabelece cinco tipos de professores: 1) Narrador de historias, 2) Historiador científico, 3) Relativista/Reformador, 4) Filósofo cósmico, 5) Eclético.

42 Alexandra CARVALHO nos fala do diferente tratamento que fazem da ditadura os professores do Brasil. Distingue os que tiveram experiências pessoais com o regime militar e os que não o tiveram. Também fala daqueles professores que se identificam com o regime militar e utilizam termos cunhados pelo regime. (CAVALHO, 2004, p. 166).

43 Rocío Trinidad, referindo-se ao caso do Peru, assinala que "a pesar do retorno da democracia, o medo e o silêncio se mantem entre os professores, com diferentes intensidades". Com isso, se coloca o problema de "... como se relacionam as memórias dos docentes com suas noções e atitudes à respeito daquele período em sua sala de aula na atualidade (TRINIDAD, 2004, p. 12).

${ }^{44}$ As atitudes de resistência da comunidade de professores com enfoques quanto à cidadania e aos temas problemáticos é sublinhado por Ernesto Gomez Rodriguez (2005, p.13). Cabe também recordar a pressão dos "pais e de grupos contra a exploração de temas problemáticos pelas crianças" (GROSS et al, 1983, p. 14). 
preenchidos, mas portadores de expectativas de futuro, de estilos de vida do presente, assim como de vivências e percepções acerca do passado próximo e da história distante. Portanto, não é possível abordar um ensino de história sem levar em consideração a situação do alunado no mundo de hoje.

Hoje em dia, de forma geral, não estamos frente a grupos homogêneos em sala de aula. A diversidade dos alunos não se refere unicamente à estrutura de gênero ${ }^{45}$ ou as diferentes classes sociais as quais os alunos pertencem, mas também abarca filhos de trabalhadores estrangeiros, filhos de asilados ou exilados, que em sala de aula enriquece novos aportes étnicos, culturais, religiosos ou empíricos ${ }^{46}$. Este novo contexto aponta para necessidade de inventar o futuro aqui e agora aproveitando o marco de convivência escolar para dar vida a um novo pacto de cidadania. Também é necessário inserir novos desafios e problemas ao ensino de história ${ }^{47}$ que deve articular diferentes memórias históricas ${ }^{48}$ e oferecer meios para que os alunos se sintam sujeitos históricos ativos e gerador de um "nós".

Entretanto, visto da perspectiva do aluno, o ensino de história oferece poucos atrativos e produz aprendizagens bastante precárias. Já nas primeiras décadas do século $X X$ os resultados não eram nada satisfatórios, o ensino de história primava pela memorização dos fatos que foram forjados para moldar a nação ${ }^{49}$. Mais recentemente, as investigações realizadas no final do século

45 Frente ao modelo de escola mista e de coeducação, ainda continua a existir em 10 comunidades autônomas escolas reformadas ligadas à Igreja Católica que defendem a educação diferenciada e segregada de meninos e meninas, mesmo que representem menos de $1 \%$ dos 21.785 colégios da Espanha (públicos, reformados e privados). (El País, n. 24, abr/2006, p. 34).

46 "As escolas do País Basco acolhem cerca de 13.700 estudantes imigrantes (colégios, institutos e centros de formação de adultos)". A porcentagem sobre o total de alunos é de 4,27\%, cifra menor que a de outras comunidades autônomas. No entanto, há 51 colégios onde a porcentagem de alunos estrangeiros supera o $20 \%$. O sistema público é que mais escolariza esse tipo de discentes, cerca de 70\% (El País, n. 24, dez/2006, p.24).

47 "Qual problemática se objetiva para o ensino de história para os 'filhos de trabalhadores estrangeiros' e os 'filhos de asilados' ou para os "filos dos exilados'" (VON BORRIES, $2006, \mathrm{p}$. 64). Segundo Bailly: "O migrante poderá descobrir em cada ambiente um passado, uma memória coletiva. A consciência de um novo lugar geram novas formas de cidadania, que a história e a geografia podem integrar paulatinamente" (BAILLY, 1998, p. 228).

48 A princípio está o problema da articulação entre a memória nacional e as diversas memórias coletivas.

49 Para o caso da França, Antoine Prost chama atenção para "as cópias e exercícios realizados nos anos 20 encontrados em Somme, não permitem nenhum triunfo: apenas a metade dos alunos que obtém certificados - e nem chegam a $50 \%$ da idade correspondente á série - são capazes responder sem erro para algumas questões básicas sobre 1789, a tomada da Bastilha ou Valmy. Apenas um em cada quatro alunos do ensino primário parece ter aprendido alguma coisa com a história, aprendem algo, mas pode ser melhor..." (PROST, 2001, p. 40). 
passado demonstraram que "muitos estudantes não aprendem o conhecimento histórico, não conseguem captar o significado do nosso passado, nem obtém uma aprendizagem significativa a partir das aulas de história na escola." (RAVISH \& FINN, 1987). Em suma, "os alunos descrevem a disciplina da história como chata, sem vida e pouco utilizável (RAVICH; FINN apud EVANS, 1991, p. $62)^{50}$ em suas vidas práticas". No começo do século XXI, não parece que a situação tenha se modificado, já que os resultados continuam destacando os "poucos conhecimentos dos estudantes referentes à cidadania, à política"51. Este cenário e a alternativa de que se deve ensinar mais história, faz com que alguns investigadores se perguntem "É a história cronológica e tradicional a melhor educação para a cidadania?" (THORNTON, 1991, p. 56) ${ }^{52}$ Fica clara a distância entre o caráter acadêmico, abstrato, conceitual e explicativo que os professores transmitem e o conhecimento cotidiano, concreto e narrativo dos alunos, o que provoca pouca motivação por parte deste, no melhor dos casos, e problemas de indisciplina e de conduta nos piores dos casos (MERCHAN, 2005, p. 38-39;45) ${ }^{53}$.

A distância colocada entre os tipos de conhecimento (história acadêmica e a de sentido prático) provocam o afastamento do passado como história. Por um lado, a vivência histórica dos alunos é reduzida, pois este tem uma experiência temporal limitada ${ }^{54}$, enquanto que, por outro lado, possuem uma vida intensa no presente, estimulada, saturada e vertiginosa ${ }^{55}$ que não está sujeita a reflexão

$50 \mathrm{Na}$ década de quarenta, foram identificados avaliações negativas iguais à respeito da história quando o assunto foi estudado nos Estados Unidos. Ver: THORNTON, S. J. "Hay que enseñar más historia?, Boletín de Didáctica de las Ciencias Sociales, n 3 y 4, 1991, p. 57-60. Publicado en Theory and Research in Social Education, Winter, 1990, v. 18, n. 1, p. 53-60. Theachers Collage, Columbia Univerity.

51 Os temas mais levantados são: Constituição, sistemas de governo 45\%; Grandes heróis: 30\%; Guerras, batalhas: 25\%; problemas atuais: $11 \%$; racismo e formas de injustiças: $9 \%$. (PAGES, 2005, p. 47-48).

52 O problema da relação entre conhecimento e consciência cívica, e da consciência cívica e da prática democrática, será sempre latente. Como acontece esta transferência?

53 Paradoxalmente, diante da prioridade que os professores dão ao caráter explicativo da história para compreensão do mundo presente, os alunos pensam que "a disciplina de história se centra nos fatos importantes e só em quinto lugar pensar que atende a compressão do presente" (MERCHAN, 2005, p. 27-28)

54 Considerando que os estudantes do primário possuem entre 6 a 12 anos e os da classe secundária entre 12 a 16 anos de vida.

55 Estes são fenômenos recentes, que apresentam claras repercussões na vida cotidiana, na saúde infantil e no clima em sala de aula. Enquanto que nos anos setenta "não se negava que poderiam ter depressão, mas até a década de oitenta não se falou do excesso de pressão que poderiam sofrer". Nos dias atuais, os transtornos de ansiedade na população infantil alcançam $8 \%$ e nos adolescentes chega a $20 \%$. Pode-se somar a esta questão casos como depressão, stress, hiperatividade, comportamentos de tirania, etc. (Diário Vasco, n. 16, abr/2006, p. 10-11) 
por parte destes. Também, estes mantêm maiores vínculos com as tecnologias que oferecem experiências de lazer do que com as histórias de vida do passado próximas à sua experiência. Os eventos que ocorreram há 15 anos estão fora de sua experiência de vida e de sua memória histórica. Assim, se perguntam "que sentido tem estudar uma coisa que não tem nada a ver com a minha vida?". Esta distância provoca no aluno uma sensação de que a história não tem nenhuma utilidade em sua vida prática e torna-se uma dificuldade e um desafio para os professores, os quais observam que "é muito difícil atualmente construir a ideia de uma relação orgânica entre passado e presente" ${ }^{\prime 56}$.

A história humana tem uma natureza coletiva que entra em contradição com os novos modelos vigentes. Os historiadores e professores que ensinam história partem da seguinte noção: A história não é o estudo do homem, "mas dos homens em sociedade". Destacando, que "as sociedades humanas, os grupos organizados" são os objetos da história (PROST, 2001, p. 154-155). Considerando o lugar particular que os alunos se encontram no mundo de hoje, observamos que a linha de desenvolvimento social das crianças com suas diferentes fases (egocentrismo, sociabilidade e fase de deveres sociais) ${ }^{57}$, assim como a sua humanização, dificulta o desenvolvimento da empatia, e aqui, nos referimos à preeminência de um novo paradigma: "o individualismo, que estimula o sujeito a reduzir sua capacidade de pensar o contexto cultural e histórico" (M. E. C. 2004, p, 95). Sobre tal questão, acrescenta-se que, por um lado, acelera-se a transição da infância para a adolescência em torno de um modelo de vida baseado no consumo, mas, por outro, alarga-se a adolescência e juventude atrasando o processo de inserção social e econômica, assim como, a compreensão por parte dos jovens de seus direitos e responsabilidades. Porém, para Lucien Febvre "quem não viveu em sociedade não pode compreender a história" (apud PROST, 2001, p. 166). Assim, a questão da ampliação do campo da experiência social e da vida seria uma questão crucial não só para os historiadores, mas também para os alunos envolvidos com a aprendizagem em

\footnotetext{
56 Para a história é fundamental a construção da noção de tempo histórico, de historicidade e atualmente isso é quase impossível para os alunos, pois o que aconteceu há cinco seria da época "dos dinossauros" (CARVALHO, 2004, p. 167).

57 Este esquema de desenvolvimento social procede de R. F. NIELSEN (1951): fase de associação ou associabilidade (0-3 anos), fase do egocentrismo (3-7 anos), fase de deveres sociais (a partir dos 13).
} 
história. A história enquanto materialização de diferentes projetos coletivos de transformação ou de resistências e disputas é uma noção complexa e incompreensível, especialmente se consideramos a esta minimização do envolvimento com assuntos públicos e a escassa consciência cidadã e política existente $^{58}$. Portanto, faltam opiniões que ressaltem que, atualmente "a tentativa de construir essa ideia de coletividade, supõe um esforço criativo muito grande para o professor" (CARVALHO, 2004, P. 167) ${ }^{59}$.

A complexidade da história foi ressaltada por Lucien Febvre, que observou que "a história está interessada por homens dotados de múltiplas funções, de diversas atividades, preocupações e atitudes que se mesclam, se chocam, se contrariam e acabam por concluir um compromisso de paz, um "modus vivendis" que denominamos Vida" (apud PROST, 2005, p. 40-41). Entretanto, hoje em dia, a complexidade da vida social se reduz ao máximo mediante visões e atitudes maniqueístas que dividem o mundo entre as forças do bem e do mal. Além disso, os meios de comunicação construíram não somente heróis e super-heróis a serem imitados, mas que tem a violência como meio de solução de conflitos, incluindo-a na prática cotidiana e estética, generalizando a violência e mostrando poucas alternativas e formas de convivência. A isto, acrescenta-se uma sociedade de consumo e espetáculo fundada no princípio de hedonismo que impulsiona uma economia, um modo de vida e um pensamento limitado baseado no que Argullol denomina "fascismo de posse imediata" (ARGULLOL, n. 24, fev., 2006, p. 13) que tem claras relações com uma nova cultura de barbárie e de violência ${ }^{60}$. Este contexto cultural de violência, consumo e espetáculo vivenciados

\footnotetext{
58 Periodicamente publicam-se pesquisas sociológicas que tratam desse desapego pelo público, mas também se menciona a forte inserção de certos setores da juventude em ONGs e movimentos sociais. Em linhas gerais encontramos "um professorado politicamente muito mais inquieto que seus estudantes" (MERCHAN, 2005, p. 16). Dados e reflexões sobre as investigações mais recentes realizadas na Europa ao final do século $X X$ podem ser verificadas neste autor nas páginas 16 e 17.

59 Ainda: "Quando nos relacionamos durante vários anos com adolescentes e jovens teremos que tratar de momentos em que se disputam projetos coletivos de transformação social, mas estas noções lhe são incompreensíveis. E quando tratamos de projetos individuais, porém, relacionados a projetos coletivos, a pergunta que mais escuto é: Eles realmente acreditavam nisso? Para os alunos é difícil construir a ideia de apostar em um projeto político e empenhar a vida neste projeto; eles não têm identificação nenhuma com este tipo de ação" (CARVALHO, 2004, p. 167).

60 É frequente aparecer manchetes como a seguinte: "80.000 pessoas protestam na Bélgica pelo assassinato de jovem de 17 anos. O mataram ao roubar-Ihe um aparelho de som" (El País, n. 24, abril, 2006, p. 9).
} 
pelos alunos também é transferido para sala de aula ${ }^{61}$ e se constitui em um obstáculo para que estes compreendam a complexidade da vida social, assim como para a construção da historicidade ${ }^{62}$, pois limita os recursos intelectuais e de convívio, necessários para gerar um pacto de cidadania, o que requer criar vínculos positivos com outras pessoas e nem tanto com os objetos.

As relações que os alunos possuem com a história são muito complexas e, envolvidas com contextos de antecedentes históricos traumáticos, tais como holocausto. Von Borries tem buscado aproximar-se da percepção que diferentes tipos de jovens têm do ensino de história em uma sociedade de imigração como a Alemanha (VON BORRIES, 2006) ${ }^{63}$. Simplificando, podemos perceber dois grandes grupos.

Por um lado, existe uma minoria onde se constata a rejeição do sentimento de vergonha, da responsabilidade direta e do envolvimento, o qual leva os jovens a negarem a procedência e a continuidade a respeito de uma sociedade que gerou o nacional-socialismo e o holocausto. É comum entre os jovens que pensam dessa forma "queixar-se que querem incutir-lhes um sentimento de culpa", pois manifestam uma mentalidade de apagamento desta história e apresentam uma nova posição hostil frente aos rituais de comemoração64.

61 É frequente ao se lidar com adolescentes a preocupação com a violência, os assassinatos, os comportamentos antissociais e as dificuldades de controle sobre tais grupos. Como resultado destas preocupações, observa-se certa preferência "por trabalhar com alunos de contextos socioculturais de classe média", também há preferência pelos cursos de bacharelado do que pela licenciatura. (MERCHAN, 2005, p. 22).

62 Esta dificuldade para construir a historicidade afeta tanto os mais individualistas, como aos integrados ou aos que padecem da violência. Extraímos este conceito de Alexandra Carvalho, que se remete a esta dificuldade, mas referindo-se especificamente ao contexto cultural das crianças que vivem nas favelas, de quem "não temos a noção da violência que sofrem. $E$ quando começamos a conversar sobre repressão, sentem uma identificação muito grande, mas ao mesmo tempo é difícil construir a historicidade; e também é muito difícil discutir os direitos humanos e os limites das ações estatais e construir com eles a cidadania a partir dos textos oficiais que lemos. O cotidiano dos alunos com o tema, tanto aproxima como aparta das conexões que podem ser realizadas com sua vida e com as experiências de outras pessoas que passaram por situações parecidas" (CARVALHO, 2004, p. 168).

63 "Entre $15 \%$ e $20 \%$ das crianças e jovens escolarizados em toda Alemanha não possuem passaporte alemão e aproximadamente a mesma quantidade são filhos de imigrantes, seja por parte de um dos progenitores ou de ambos, por isso a Alemanha é, objetivamente um país de imigração" (VON BORRIES , 2006, p. 73).

64 Esta mentalidade e esta hostilidade alcançam cerca de $20 \%$ dos estudantes. Algumas manifestações desta mentalidade aparecem da seguinte forma: "o fato de que os sobreviventes não deixem de lembrar a todo mundo que nossos avós mataram tantos judeus, é algo que não podemos jamais Ihes perdoar" (VON BORRIES, 2006, p. 71). Sobre a caracterização deste grupo "hostil", ver páginas 67-72. 
Por outro lado, existe um grande grupo de estudantes politicamente corretos que alcançam $87 \%$ entre aqueles que predominantemente têm "implicações morais" sobre tais acontecimentos. Entretanto, essa noção é pouco precisa, pois "consiste em indignação, compreensão, auto piedade, pesar ou medo". Portanto, podemos perguntar, quanto dessa porcentagem se identifica também com um sentido de "compromisso com uma memória digna que enfrenta a constante ameaça de genocídio?" ${ }^{65}$.

Hoje em dia, o abismo gerado em torno de tais questões e a distância com o passado faz com que o perigo de se ter esquecido tais traumas, seja cada vez mais patente, já que estamos passando da "terceira geração de atores para a quarta" e os estudos indicam que "as implicações são herdadas até a terceira e quarta geração" (VON BORRIES, 2006, p.67-68). Este problema se torna mais agravante em uma sociedade de imigração, que deveria repensar o ensino de história e que não deve deixar esquecer este passado ${ }^{66}$, o que não se traduz em garantias de coesão e integração, mas que permite que o horror não seja novamente possível para as novas gerações, com os novos sujeitos, de modo que segundo Borries, "Os novos alemães devem incluir a necessidade de adotar como elemento próprio da identidade o lado negativo do holocausto, ainda que tal questão pese a estes; caso contrário não seriam alemães" (VON BORRIES, 2006, p. 73) ${ }^{67}$.

Assumir esta herança, não quer dizer que é algo circunscrito a toda nação, mas que devem ser parte da bagagem da nossa condição humana, já que a ameaça de extermínio do outro se tornou real e se materializou em diferentes cenários (Camboja, em países da ex-Iugoslávia, Ruanda...) e nenhum Estado, nenhum povo está livre deste perigo e de outros como a xenofobia, o racismo e a violência sectária.

\footnotetext{
65 Os dados dos textos apontados por Von Borries se baseiam na investigação de Brusten e Winkelman de 1994 (VON BORRIES, 2006, p. 72). Este autor também inclui outras pesquisas. Assim, 28\% dos estudantes (politicamente corretos) reconhecem ter sentimento de culpa, mas em outros estudos se reduzem a 7\% (investigação de Pohl de 1996) (VON BORRIES, 2006, p. $67)$.

66 "O esquecido, que é equivocar-se historicamente, é um fator essencial na invenção de uma nação, daí que o avanço dos estudos históricos representa um risco para a nacionalidade". (RENAN, 2001, p. 35).

67 Sobre o horror "ser possível" ver páginas 70 e 71.
} 


\section{Considerações finais}

- $\quad$ Devemos formular retóricas que legitimam um ensino de história que gere novas práticas educativas. O modelo com base na identidade nacional apresenta-se muito limitado para compreender os cenários complexos atuais. Junto à noção de identidades múltiplas devem-se ressaltar os processos de interação e interdependência em todas suas dimensões.

- $\quad$ Em um mundo globalizado e dinâmico não tem mais sentido manter um modelo de educação tradicional, devemos repensar o ensino a história a partir de uma perspectiva e de um questionamento que leve a uma participação cívica e cidadã dos estudantes.

- $\quad$ A invenção do futuro requer para práticas pautadas na cidadania e inventivas em relação à convivência social, mas também devemos recordar os erros e o quanto custaram estas práticas antissociais e violentas, evitando atitudes de relativização, banalização e desprezo mútuo.

- $\quad$ Por último, se queremos capacitar as novas gerações para conviver em sociedade e dar recursos para inventar o futuro, devemos recordar que tal tarefa não é exclusiva da escola, mas da sociedade como um todo, conectada entre si, que parte das análises das carências e déficits que padece esta sociedade e que também deve fazer uso de tais práticas voltadas para a construção da cidadania.

\section{Referências}

ALTAMIRA, R. La enseñanza de la Historia en España. Memória presentada à Comissão Internacional para o ensino da história. In: MUSEO PEDAGOGICO NACIONAL, La enseñanza de la Historia en las Escuelas. Bulletín du Comité International des Sciences Históriques. v. I, Madrid, 1934.

ARGULLOL, R. El fascismo de la posesión inmediata. El País, Madrid, n. 24, fev/2006.

ARON, R. Lecciones sobre la historia. Curso de Collège de France. México: FCE, 1996.

BAILLY, A. La Educación para las Nuevas ciudadanías mediante la Historia y la Geografía: enfoque teórico. Perspectivas, v. 2, n. 28, 1998. p. 223-227. 
BASTIDA, A. Desaprender la guerra. Una visión crítica de la educación para la paz. Barcelona: Icaria, 1994.

BERGER, P.; BERGER, B. Un mundo sin hogar. Modernización y conciencia, Santander, 1979.

BLOCH, Ernst, El Principio de la Esperanza. Madrid: Aguilar. 1977.

CARVALHO, A. Realidades y desafíos: experiencias educativas en Argentina, Uruguay y Brasil. In: JELIN, E.; LORENZ, F.G. (Org.). Educación y memoria. La escuela elabora el pasado. Madrid: Siglo XXI, 2004.

CRUZ, M. Las malas pasadas del pasado. Identidad, responsabilidad, historia. Barcelona: Anagrama, 2005.

CUESTA FERNÁNDEZ, R. Clio en las aulas. La enseñanza de la Historia en España entre reformas, ilusiones y rutinas. Madrid: Akal, 1998.

DEL OLMO PINTADO, M.; HERNANDEZ SANCHEZ, C. Identidad y educación. Una perspectiva teórica. Iber, n. 47, jan./mar. 2006.

DIAMOND, J. C. Por qué unas sociedades perduran y otras desaparecen. Debate. Madrid, 2006.

DIÁRIO VASCO. San Sebastian. 16, abr/2006.

EVANS, R. W. Concepciones del maestro sobre la historia. Boletín de Didáctica de las Ciencias Sociales. Asociación Universitaria de Profesores de Didáctica de las Ciencias Sociales. n. 3 /4, 1991. p. 61-94. (Publicado originalmente em Theory and Research in social Education. v. XVII, n. 3, p. 210-240).

GARTON ASH, T. Qué hacer con la bandera del imperio. Identidad británica. El País. Madrid, n. 22, jan/2006.

GOMEZ RODRIGUEZ, E. Tendencias en la educación ciudadana en el siglo XXI. Iber. Didáctica de las Ciencias Sociales, Geografía e Historia. n. 44, abril, 2005.

GONZÁLEZ LINACERO, D. Mi primer libro de historia. Palencia, 1933.

GROSS, R.E.; MESSICK, R; CHAPIN, J. R.; SUTHERLAND, J. Ciencias Sociales. Programas actualizados de Enseñanza. México: Limusa, 1983.

HALBWACHS, M. Los marcos sociales de la memoria. Barcelona: Anthropos, 2004 HOBSBAWM, E. Historia del siglo XX. Barcelona: Crítica, 1995.

INNERARITY, Daniel. La sociedad invisible. Madrid: Espasa Calpe, 2004.

INRP. MUSEE NATIONAL DE L'EDUCATION. Comme Patrie (en France entre 1850-1950). Exposition jul.1988/jun.1989.

JARES, J. R., Educación para la paz. Su teoría y su práctica. Madrid: Editorial Popular, 1991.

JELIN, E.; LORENZ, F. G. Educación y memoria: entre el pasado, el deber y la posibilidad" In: . JELIN, E.; LORENZ, F.G. (Org.). Educación y memoria. La escuela elabora el pasado, Madrid: Siglo XXI, 2004. 
LORENZ, F. Realidades y desafíos: experiencias educativas en Argentina, Uruguay y Brasil. In: JELIN, E.; LORENZ, F.G. (Org.). Educación y memoria. La escuela elabora el pasado. Madrid: Siglo XXI, 2004.

MARTINEZ ABELLAN, P. Lecciones de Historia de España al alcance de los niños que concurren a nuestras escuelas elementales y superiores. Madrid: Librería de Perlado, Páez y Ca (Sucesores de Hernando). 1903.

MERCHAN, F. J., Enseñanza, examen y control. Profesores y alumnos en la clase de historia. Barcelona: Octaedro-EUB, 2005.

MUCHIELLI, A. L'identite. Colección Que sais-je? París: P. U. F. 2006 .

ORTIZ DE ORRUÑO, J. M. Historia y sistema educativo. Ayer, n. 30, 1998.

PAGES, J. Educación cívica, formación política y enseñanza de la geografía y la historia. Iber. Didáctica de las Ciencias Sociales, Geografía e Historia. n. 44, abr. 2005.

PORCEL; RIERA, M. Curso completo de Enseñanza Primaria. Escrito con arreglo al método cíclico. Palma de Mallorca: Grado preparatorio, 1937.

PROST, A. Doce lecciones sobre la Historia. Valencia: Frónesis-Cátedra, 2001.

RENAN, E. ¿Qué es uma nación? Madrid: Sequitur 2001.

SARTORI, G. Homo videns. La sociedad teledirigida. Madrid: Taurus, 2001.

SERRANO DE HARO, A. Yo soy español. Madrid: Editorial Escuela Española, 1962.

TABA, H. Elaboración del currículo. Teoría y práctica, Buenos Aires: Troquel, 1974.

THORNTON, S. J. Hay que enseñar más historia? Boletín de Didáctica de las Ciencias Sociales. n. 3/4, 1991.

TRINIDAD, R. El espacio escolar y las memorias de la guerra en Ayacucho. In: JELIN, E.; LORENZ, F.G. (Org.). Educación y memoria. La escuela elabora el pasado. Madrid: Siglo XXI, 2004.

VATTIMO, G. El fin del sentido emancipador de la historia. El País, Madrid, n. 6, dez/1986.

VON BORRIES, B. "!Qué nos importa vuestra historia!". Enseñanza de historia en una sociedad de inmigración. Iber, n. 47, mar. 2006.

WALLERSTEIN, I. Las incertidumbres del saber. Barcelona: Gedisa, 2005.

Tradução autorizada pelo autor em 01 de março de 2013. 